\title{
LY294002 inhibits the Warburg effect in gastric cancer cells by downregulating pyruvate kinase M2
}

\author{
JIAN LU ${ }^{1-3^{*}}$, MIN CHEN $^{1,3^{*}}$, SUMENG GAO $^{3}$, JIGANG YUAN $^{3}$, ZHU ZHU $^{3}$ and XIAOPING ZOU ${ }^{1,3}$ \\ ${ }^{1}$ Department of Gastroenterology, The Affiliated Drum Tower Clinical Medical School of Nanjing Medical University, \\ Nanjing, Jiangsu 210008; ${ }^{2}$ Department of Gastroenterology, The Affiliated Wuxi Second Hospital of \\ Nanjing Medical University, Wuxi, Jiangsu 214002; ${ }^{3}$ Department of Gastroenterology, \\ The Affiliated Drum Tower Hospital of Nanjing University, Medical School, Nanjing, Jiangsu 210008, P.R. China
}

Received September 4, 2016; Accepted November 29, 2017

DOI: $10.3892 / 01.2018 .7843$

\begin{abstract}
The 'Warburg effect' is considered a vital hallmark of cancer cells, characterized by an altered metabolism, in which cells rely on aerobic glycolysis. As a key enzyme of aerobic glycolysis, pyruvate kinase M2 (PKM2) serves a crucial role in tumorigenesis. Accumulating studies have indicated that PKM2 is a potential target for cancer therapy. The aim of the present study was to assess the anticancer effects of LY294002, a specific phosphatidylinositol-3-kinase inhibitor, on gastric cancer (GC) cells and further explore its possible mechanism in vitro. The present study revealed that LY294002 inhibited GC cell proliferation, induced early apoptosis and significantly decreased lactate dehydrogenase activity and lactate production, in part through inhibiting PKM2 expression. In summary, LY294002 exhibits anticancer effects on GC, partly via the downregulation of PKM2.
\end{abstract}

\section{Introduction}

Gastric cancer (GC) is a multifactorial disease (1), which occurs frequently worldwide and is ranked as the second most common cause of cancer-associated mortality $(13.3 \%, 2012)(2)$. Tumorigenesis and tumor development depend, in part, on the reprogramming of tumor metabolism $(3,4)$. Targeting tumor metabolism may be a potential therapeutic strategy in directing treatment for GC (5-7).

Correspondence to: Dr Min Chen or Professor Xiaoping Zou, Department of Gastroenterology, The Affiliated Drum Tower Clinical Medical School of Nanjing Medical University, 321 Zhongshan Road, Nanjing, Jiangsu 210008, P.R. China

E-mail: croweminchan@aliyun.com

E-mail: 13770771661@163.com

${ }^{*}$ Contributed equally

Key words: LY294002, gastric cancer, Warburg effect, pyruvate kinase M2, glycolysis
Aerobic glycolysis is a phenotypic characteristic of cancer metabolism, which is known as the 'Warburg effect'. Pyruvate kinase (PK) is the key enzyme which catalyzes the dephosphorylation of phosphoenolpyruvate (PEP) to pyruvate at the final step of glycolysis to release energy (8). A total of 4 isoenzymes of pyruvate kinases: PKM1; PKM2; PKL; and PKR, have been identified in mammals (9). Among them, PKM1 is present in the majority of adult tissues, and as a splice variant of PKM1, PKM2 has been identified in fetal tissues, adult stem cells and various cancer cells (10-12). PKM2, which controls the final rate-limiting step of glycolysis, is crucial for aerobic glycolysis. Numerous studies have revealed that tumor cells exclusively express PKM2, including hepatocellular carcinoma (13), human glioblastoma (14), prostate cancer (15), breast cancer (16), cholangiocarcinoma (17) and gastric cancer (18-20). Additionally, increased expression levels of PKM2 result in metastasis and poor prognosis for patients with cancer (21-23). Thereby, PKM2 is important in the cancer progression as a key regulator of Aerobic glycolysis. Hence, knockdown PKM2 inhibited cell proliferation, glucose metabolism and suppressed the growth of xenografts (24). Targeting PKM2 is a possible mechanism for reducing the 'Warburg effect' of GC and influencing the tumor microenvironment, which may facilitate the potential development of PKM2-targeted therapy for GC.

PKM2, is a critical downstream mediator of the phosphatidylinositol-3-kinase/protein kinase B/mechanistic target of rapamycin (PI3K/Akt/mTOR) signaling pathway (25). Multiple studies have demonstrated that the P13K/Akt/mTOR signaling pathway may be associated with cell proliferation and survival, with the induction of apoptosis and with tumor glucose metabolism $(26,27)$. The present study aimed to investigate whether LY294002, a specific P13K inhibitor, could inhibit proliferation, induce apoptosis and inhibit the Warburg effect in GC cells, potentially by downregulating PKM2.

\section{Materials and methods}

Cell lines and culture. Various human GC cell lines, including SGC-7901 (moderately differentiated), BGC-823 (poorly differentiated) and immortalized normal gastric epithelium cells (GES-1), and the human cervical cancer HeLa cell line 
were provided by the Department of Oncology, The Affiliated Drum Tower Hospital of Nanjing University, Medical School, (Nanjing City, Jiangsu Province). HeLa cell lines were used as a positive control for the present study. Cells were cultured in RPMI1640 (Hyclone, Logan, UT, USA) supplemented with $10 \%$ fetal bovine serum (Hangzhou Sijiqing Biological Engineering Materials Co., Ltd., Hangzhou, China) and 100 units $/ \mathrm{ml}$ penicillin and $100 \mu \mathrm{g} / \mathrm{ml}$ streptomycin in a humidified air with $5 \% \mathrm{CO}_{2}$ at $37^{\circ} \mathrm{C}$ (Thermo Fisher Scientific, Inc., Waltham, MA, USA).

Cell transfection. A pU6 plasmid, synthesized by Shanghai GeneChem Co., Ltd., (Shanghai, China), containing siRNA targeting PKM2 mRNA and empty plasmids as the negative control were transfected into the SGC-7901 cells using Lipofectamine ${ }^{\circledR} 2000$ (Invitrogen; Thermo Fisher Scientific, Inc.), according to the manufacturer's protocol. Cells were cultured and selected in medium containing $400 \mathrm{mg} / \mathrm{ml} \mathrm{G} 418$ (Santa Cruz Biotechnology, Inc., Dallas, TX, USA).

Cell viability assay. Cell survival rate was assessed by using a Cell Counting Kit-8 (CCK-8) assay (KeyGen Biotech Co., Ltd., Jiangsu Province, P.R. China), according to the manufacturer's protocol. BGC-823 cells were plated at a density of $1 \times 10^{4}$ cells/well in $100 \mu 1 \mathrm{RPMI}-1640$ (Hyclone) into 96-well plates and cultured for $24 \mathrm{~h}$ ( $\sim 80 \%$ confluent). Cells were then treated with LY294002 at various concentrations $(0$, $10,20,50,100 \mu \mathrm{mol} / \mathrm{l})$, or with DMSO $(0.2 \%)$ as a control, for 24 and 48 h. SGC-7901 cells from the non-transfected, negative control (empty plasmid) and PKM2-siRNA groups were plated at a density of $1 \times 10^{4}$ cells/well in 96-well plates and cultured at $37^{\circ} \mathrm{C}$ for $24-48 \mathrm{~h}$. The absorbance was measured at $450 \mathrm{~nm}$ using a Cell Counting Kit-8 assay (Nanjing KeyGen Biotech Co., Ltd., Nanjing, China).

Annexin V-fluorescein isothiocyanate (FITC) apoptosis assay. BGC-823 cells were plated into 6 -well plates at a density of $1 \times 10^{6}$ cells/well. Following treatment with the indicated concentrations of LY294002 (0, 10, 20, 50, $100 \mu \mathrm{mol} / \mathrm{l})$, or DMSO (0.2\%) for $48 \mathrm{~h}$, the cells were dual-stained using an Annexin V-FITC kit (Nanjing KeyGen Biotech Co., Ltd.). SGC-7901 cells from the non-transfected, negative control and PKM2-siRNA groups were seeded at a density of $1 \times 10^{6}$ cells/well in 6 -well plates and cultured to $80 \%$ confluence for $48 \mathrm{~h}$, and then the aforementioned dual staining was performed. Apoptotic cells were detected by flow cytometry using BD FACSCalibur flow cytometer (BD Biosciences, Franklin Lakes, NJ, U.S.A.). BD FACSDiva software was used to analyze data (version 7.0, BD Biosciences, U.S.A.).

Western blotting analysis. The protein expression level of PKM2 was evaluated in each cell line (SGC-7901, BGC-823, GES-1 and HeLa cells) by western blot analysis. The protein levels of p-Akt, p-mTOR, hypoxia inducible factor-1 $\alpha$ (HIF-1 $\alpha$ ) and PKM2 were assessed in BGC-823 cells, and PKM2, Glut-1 and LDHA expression levels in SGC-7901 cells of the non-transfected, negative control and PKM2-siRNA groups were evaluated by western blot analysis. Total cell extracts were prepared on ice for $30 \mathrm{~min}$ in lysis buffer $(150 \mathrm{mM}$ $\mathrm{NaCl}, 50$ mM Tris-HCl, $\mathrm{pH}$ 8.0, 0.1\% SDS, 0.2\% EDTA, $1 \%$
Triton X-100, 1\% sodium deoxycholate and 0.01\% PMSF) and supplemented with protease inhibitors (aprotinin, leupeptin, phenylmethylsulfonyl fluoride, sodium orthovanadate; Roche Diagnostics, Basel, Switzerland), and centrifuged at 9,660 x g in $4^{\circ} \mathrm{C}$ (cat. no. 5804R; Eppendorf, Hamburg, Germany) for $15 \mathrm{~min}$ to remove nuclei and cell debris. Additionally, tumor samples were subjected to homogenate ahead of total cell extracts. Protein concentration was quantified using the bicinchoninic assay kit (Nanjing KeyGen Biotech Co., Ltd., China), according to the manufacturer's protocol. In total, $50 \mu \mathrm{g}$ of each protein sample loaded onto SDS-PAGE (10\%) and transferred on to polyvinylidene fluoride membranes (Immobilon ${ }^{\circledR}-\mathrm{P}$; Sigma-Aldrich; Merck KGaA, Darmstadt, Germany) using a semi-dry transfer system (Bio-Rad Laboratories, Inc., Hercules, CA, USA). Non-specific binding was blocked by incubating the membranes in $1 \mathrm{X}$ TBS containing $0.05 \%$ Tween-20) supplemented with $5 \%$ non-fat dry milk for $1 \mathrm{~h}$. Blots were incubated at $4^{\circ} \mathrm{C}$ overnight with monoclonal rabbit antibodies against PKM2 (cat. no. 4053, dilution, 1:1,000; Cell Signaling Technology, Inc., Danvers, MA, U.S.A.), p-Akt (cat. no. 13038, dilution, 1:1,000; Cell Signaling Technology, Inc.), p-mTOR (cat. no. 5536, dilution, 1:1,000; Cell Signaling Technology, Inc.), HIF-1 $\alpha$ (cat. no. 36169, dilution, 1:1,000; Cell Signaling Technology, Inc.) glucose transporter-1 (cat. no. 12939, dilution, 1:1,000; Cell Signaling Technology, Inc.) and lactate dehydrogenase A (cat. no. 3582, dilution, 1:1,000; Cell Signaling Technology, Inc.) and a monoclonal mouse antibody to $\beta$-actin (cat. no. sc-130300, 1:3,000; Santa Cruz Biotechnology, Inc., Dallas, TX, U.S.A.) was used as an internal control. Blots were then incubated with horseradish peroxidase-conjugated goat anti-mouse antibody (No. 074-1806, dilution, 1:1,000; KPL, Inc., Gaithersburg, MD, USA) and/or goat anti-rabbit antibody (cat. no. L3012, dilution, 1:1,000; KPL, Inc.). Antibody staining was visualized using enhanced chemiluminescence Western Blot Substrate (Pierce; Thermo Fisher Scientific, Inc.) The images of western blot products were collected and analyzed using Quantity One V4.31 (Bio-Rad Laboratories, Inc.).

Immunofluorescence analysis. BGC-823 cells were seeded at a density of $1 \times 10^{6}$ cells/well into 6-well plates, prior to treatment with LY294002 $(0,50$ or $100 \mu \mathrm{mol} / \mathrm{l})$ or with DMSO $(0.2 \%)$ (2 $\mu \mathrm{l} /$ well) for $48 \mathrm{~h}$ at $37^{\circ} \mathrm{C}$. Subsequent to washing with PBS 3 times, the cells were fixed with cold acetone for $10 \mathrm{~min}$ at $4^{\circ} \mathrm{C}$. Next, the cells were blocked with $10 \%$ normal goat serum (Wuhan Boster Biological Technology, Ltd., Wuhan, China) for $30 \mathrm{~min}$ and probed with an antibody against PKM2 (cat. no. 4053, dilution, $1: 100$, Cell Signaling Technology, Inc.) at $4^{\circ} \mathrm{C}$ overnight. Alexa Fluor dye conjugated secondary antibodies ( $2 \mathrm{mg} / \mathrm{ml}$ goat anti-rabbit $\mathrm{IgG}(\mathrm{H}+\mathrm{L})$ highly cross-absorbed) (cat. no. R37117, Alexa Fluor 594; dilution, 1:1,000; Invitrogen; Thermo Fisher Scientific, Inc.) were incubated with cells for $1 \mathrm{~h}$ at $20^{\circ} \mathrm{C}$ to enable the samples to be visualized under a fluorescent microscope (Axio Imager A1; Carl Zeiss AG, Oberkochen, Germany). The nuclei were stained using DAPI ( $2 \mu \mathrm{g} / \mathrm{ml}$; Invitrogen; Thermo Fisher Scientific, Inc.) for $15 \mathrm{~min}$ under dark conditions at $20^{\circ} \mathrm{C}$.

RNA isolation and reverse transcription polymerase chain reaction (RT-qPCR) assay. Total RNA from SGC-7901 cells of the non-transfected, negative control and PKM2-siRNA groups 
were extracted using TRIzol reagent (Invitrogen; Thermo Fisher Scientific, Inc.) according to the manufacture's protocol. The first-strand cDNA was synthesized using High-Capacity cDNA Reverse Transcription kit (Applied Biosystems; Thermo Fisher Scientific, Inc.). RT-primers of LAT-1 mRNAs were designed and synthesized as follows: Forward, 5'-AGT ACCATGCGGGACCATC-3' and reverse, 5'-GCGTTATCC AGCGTGATTTT-3' (Invitrogen; Thermo Fisher Scientific, Inc.). Real-time quantitative polymerase chain reaction (qRT-PCR) was performed according to the TaqMan Gene Expression Assays protocol (Applied Biosystems; Thermo Fisher Scientific, Inc.) (28). The PCR program was as follows: $95^{\circ} \mathrm{C}$ for $10 \mathrm{~min}$, followed by 32 cycles of $95^{\circ} \mathrm{C}$ for $15 \mathrm{sec}, 60^{\circ} \mathrm{C}$ for $30 \mathrm{sec}$ and $72^{\circ} \mathrm{C}$ for $45 \mathrm{sec}$. Fold-induction was calculated using the formula $2^{-\Delta \Delta \mathrm{Ct}}(29)$.

LDH activity and lactate assay. BGC-823 cells were seeded at a density of $1 \times 10^{4}$ cells/well into 96 -well plates and subsequently treated with 0 or $50 \mu \mathrm{mol} / 1 \mathrm{LY} 294002$ for $48 \mathrm{~h}$. SGC-7901 cells of the non-transfected, negative control and PKM2-siRNA groups were cultured for $48 \mathrm{~h}$ at $37^{\circ} \mathrm{C}$. LDH activity was determined using an LDH Cytotoxicity Assay kit (Beyotime Institute of Biotechnology, Haimen, China). Lactate in the culture medium was determined using a Lactate Assay kit (Nanjing Jiancheng Bioengineering Institute, Nanjing, China).

Statistical analysis. The data are expressed as the mean \pm standard deviation, and analyzed by using Least Significant Difference and Student Newman-Keuls methods following analysis of variance and the Student's t-test method. The data were analyzed using SPSS v.19.0 software (IBM Corp., Armonk, NY, USA). P $<0.05$ was considered to indicate a statistically significant difference.

\section{Results}

Expression of PKM2 is upregulated in GC cell lines. Western blot analysis demonstrated that, PKM2 expression was significantly increased in GC cell lines (SGC-7901, BGC-823) and HeLa cells, compared with in the GES-1 cells (Fig. 1A; P<0.05).

Effects of LY294002 on proliferation and apoptosis in BGC-823 cells. Cell viability of BGC-823 cells, following LY294002 inhibitor treatment was assessed using a CCK-8 assay. As illustrated in Fig. 1B, LY294002 was able to inhibit the proliferation of BGC-823 cells in vitro. Cell viability in the $20 \mu \mathrm{mol} / 1 \mathrm{LY} 294002$ group was significantly decreased $(91.64 \pm 3.06 \%$ vs. $100 \%$ for the control group; $\mathrm{P}<0.05)$, compared with the control group. This was observed as a doseand time-dependent decrease in the viability of BGC-823 cells following LY294002 treatment. Furthermore, it was demonstrated that, in response to LY294002 treatment, the early apoptotic rate was significantly increased in the BGC-823 cells compared with the control group, in a dose-dependent manner (50 and $100 \mu \mathrm{mol} / 1$ LY294002; Fig. 1C; P<0.05).

Effects of LY294002 on p-Akt, p-mTOR, HIF- $1 \alpha$ and PKM2 in the BGC-823 cells. To evaluate whether LY294002 can inhibit p-AKT, p-mTOR, HIF-1 $\alpha$ and PKM2 expression, BGC-823 cells treated with $0,10,20,50$ or $100 \mu \mathrm{mol} / 1 \mathrm{LY} 294002$ and DMSO for $48 \mathrm{~h}$ were assessed via western blotting and immunofluorescence. Following $10 \mu \mathrm{mol} / \mathrm{l} \mathrm{LY} 294002$ treatment for $48 \mathrm{~h}, \mathrm{p}-\mathrm{AKT}$ and $\mathrm{p}$-mTOR expression were decreased when compared with in the control group $(\mathrm{P}<0.05)$. Furthermore, HIF-1 $\alpha$ expression was reduced following treatment with $20 \mu \mathrm{mol} / 1 \mathrm{LY} 294002$ for $48 \mathrm{~h}$; and PKM2 expression decreased following treatment with $50 \mu \mathrm{mol} / 1 \mathrm{LY} 294002$ at $48 \mathrm{~h}$. A dose-dependent association was revealed between the LY294002 concentration and the expression levels of p-AKT, p-mTOR, HIF-1 $\alpha$ and PKM2 (Fig. 2A). In addition, the intracellular distribution of PKM2 in BGC-823 cells was detected, revealing that PKM2 was distributed around the nucleus and the expression decreased following treatment with LY294002 (Fig. 2B).

Effects of LY294002 on LDH activity and lactate production in BGC-823 cells. To determine the effects of LY294002 on LDH activity and lactate production in BGC-823 cells, LDH activity and lactate production were measured. LDH activity (Fig. 2C) and lactate production (Fig. 2D) in the $50 \mu \mathrm{mol} / 1$ LY294002 group were significantly decreased compared with in the control group $(\mathrm{P}<0.05)$.

Knockdown of PKM2 suppresses proliferation, induces apoptosis and inhibits the Warburg effect in SGC7901 cells. PKM2 vectors downregulating the plasmid or control plasmid (non-transfected group and empty plasmid group) were transfected into the SGC-7901 cells according to the protocol aforementioned. The expression levels of PKM2 were analyzed by RT-qPCR and immunoblotting. PKM2-siRNA decreased the mRNA (Fig. 3A) and protein (Fig. 3B) levels of PKM2 ( $\mathrm{P}<0.05)$. A CCK-8 assay demonstrated significant time-dependent inhibition of SGC-7901 cell proliferation following the knockdown of PKM2 (Fig. 4A; $\mathrm{P}<0.05$ ). It was further revealed that the early apoptosis rate of SGC-7901/PKM2-siRNA cells was increased compared with that of the control cells (Fig. 4B; $\mathrm{P}<0.05$ ). These results indicated that PKM2 was able to promote the proliferation and suppress the apoptosis of GC cells. To determine whether PKM2 knockdown exerts any influence on the Warburg effect in SGC7901 cells, LDH activity and lactate production were measured. Compared with the control groups, LDH activity (Fig. 4C) and lactate production (Fig. 4D) in SGC7901 cells of the siRNA-PKM2 group was significantly decreased $(\mathrm{P}<0.05)$. Western blotting demonstrated that the knockdown of PKM2 significantly decreased Glut-1 and LDHA protein expression levels (Fig. 4E), compared with in the non-transfected or empty plasmid groups. In combination, these outcomes indicate that PKM2-knockdown in SGC-7901 cells was associated with the Warburg effect.

\section{Discussion}

The P13K/AKT/mTOR signaling pathway serves a crucial role in transduction, which regulates cell proliferation, survival, migration and metabolism $(26,27,30,31)$. Accumulating evidence has demonstrated that activation of the P13K/Akt/mTOR signaling pathway may be involved in the initiation and progression of numerous types of cancer, 

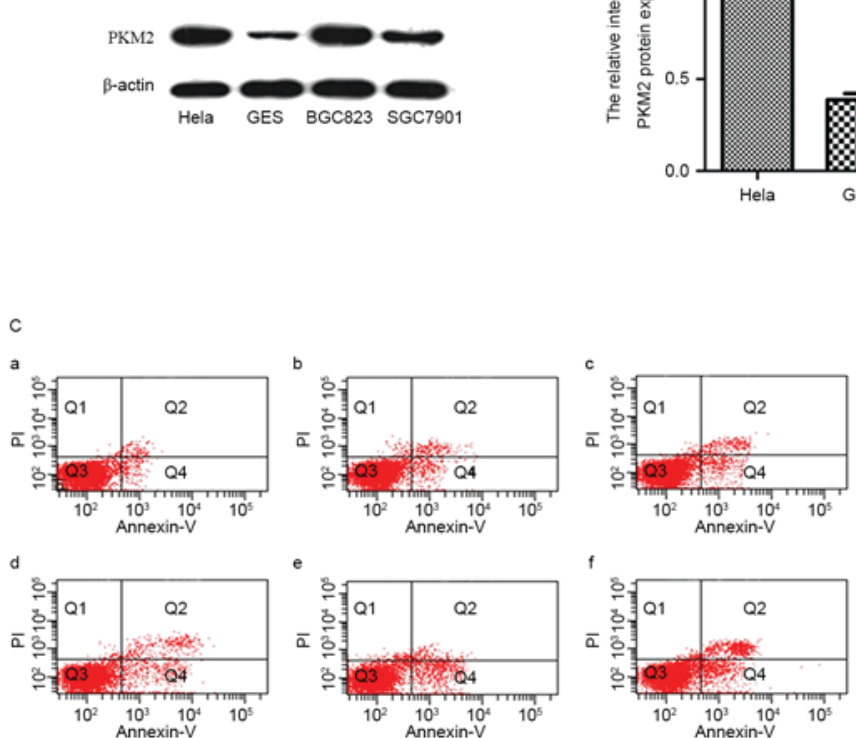

a:Ly294002 0 umoll?:

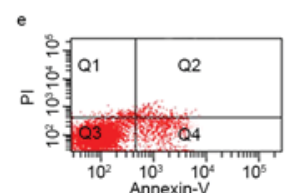

b: DMSO

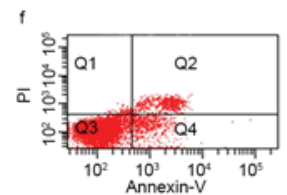

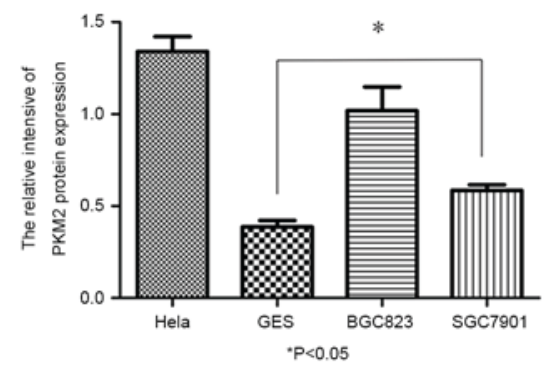

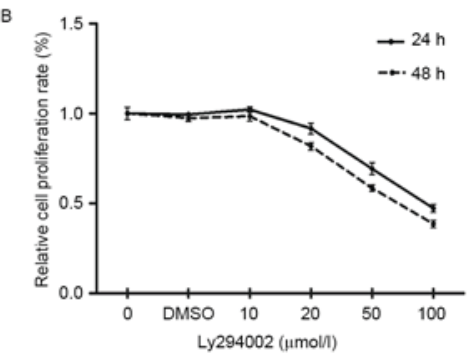

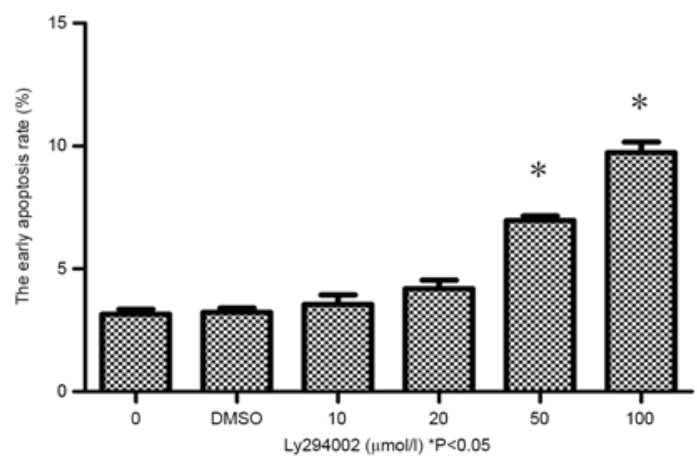

Figure 1. Expression of PKM2 in GC lines was significantly upregulated. LY294002 inhibits the viability of and induces early apoptosis in GC cells. (A) PKM2 protein expression in GC cell lines (SGC-7901, BGC-823 and HeLa), as detected via western blot analysis, was significantly upregulated compared with in GES-1 cells. (B) Evaluation of BGC-823 cell viability, following treatment with LY294002 (0-100 mM) or DMSO for 24 and $48 \mathrm{~h}$. (C) Evaluation of the early apoptotic rate of BGC823 cells following treatment with LY294002 (0, 10, 20, 50 or $100 \mu \mathrm{mol} / \mathrm{l})$ or DMSO for $48 \mathrm{~h}$. "P<0.05 vs. control. PKM2, pyruvate kinase M2; GC, gastric cancer; LY294002, PKM inhibitor; DMSO, dimethyl sulfoxide.
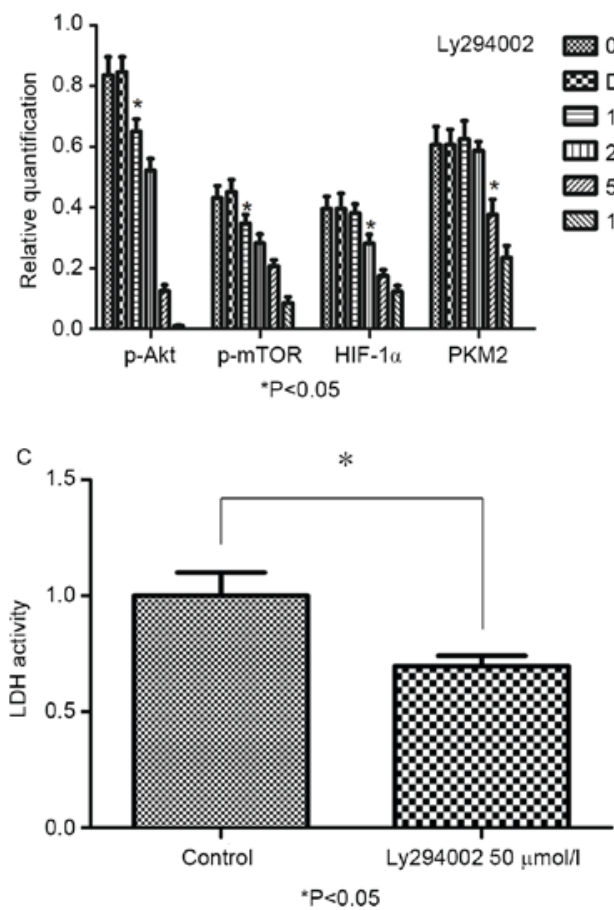
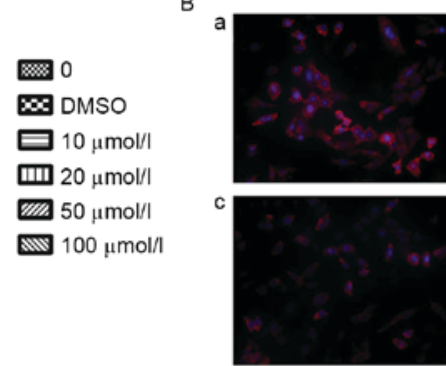

a:Ly294002 $0 \mu \mathrm{mol} / \mathrm{l}$; Ly294002 50, $100 \mu \mathrm{mol} / \mathrm{l}$

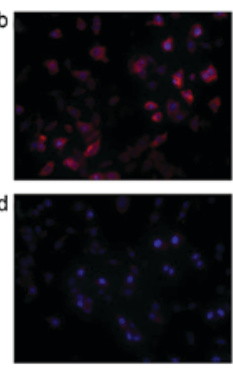

b: DMSO; c, d:

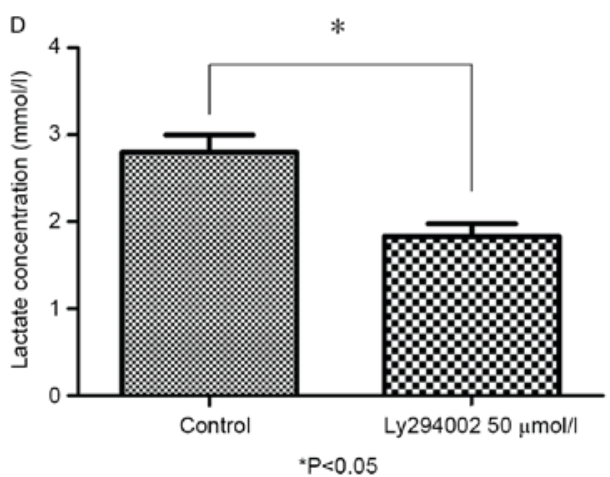

Figure 2. LY294002 reduces p-AKT, p-mTOR, HIF-1 $\alpha$ and PKM2 protein expression, and inhibits LDH activity and lactate production in BGC-823 cells. (A) Protein expression of p-mTOR, HIF-1 $\alpha$ and PKM2 in BGC-823 cells treated with LY294002 (0, 10, 20, 50 or 100 $\mu$ mol/1) or DMSO for 48 h, as detected by western blot analysis (B) Double immunofluorescence staining revealed the intracellular distribution of PKM2 in BGC-823 cells prior to and following LY294002 treatment, at x200 magnification. (B, a) Intracellular distribution of PKM2 in BGC-823 cells without LY294002 treatment. (B, b) Intracellular distribution of PKM2 in BGC-823 cells with DMSO. (B, c) Intracellular distribution of PKM2 in BGC-823 cells treated with $50 \mu$ mol/1 LY294002 for 48 h. (B, d) Intracellular distribution of PKM2 in BGC-823 cells treated with $100 \mu \mathrm{mol} / 1 \mathrm{LY} 294002$ for $48 \mathrm{~h}$. (C) LDH activity significantly decreased after $48 \mathrm{~h}$ of treatment with $50 \mu \mathrm{mol} / 1 \mathrm{LY} 294002$. (D) Lactate production significantly decreased after $48 \mathrm{~h}$ of treatment with $50 \mu \mathrm{mol} / 1 \mathrm{LY} 294002$. * $<0.05 \mathrm{vs}$. control. p-AKT, phospho-protein kinase B; p-mTOR, phospho-mechanistic target of rapamycin; HIF-1 $\alpha$, hypoxia inducible factor-1 $\alpha$; PKM2, pyruvate kinase M2; DMSO, dimethyl sulfoxide. 

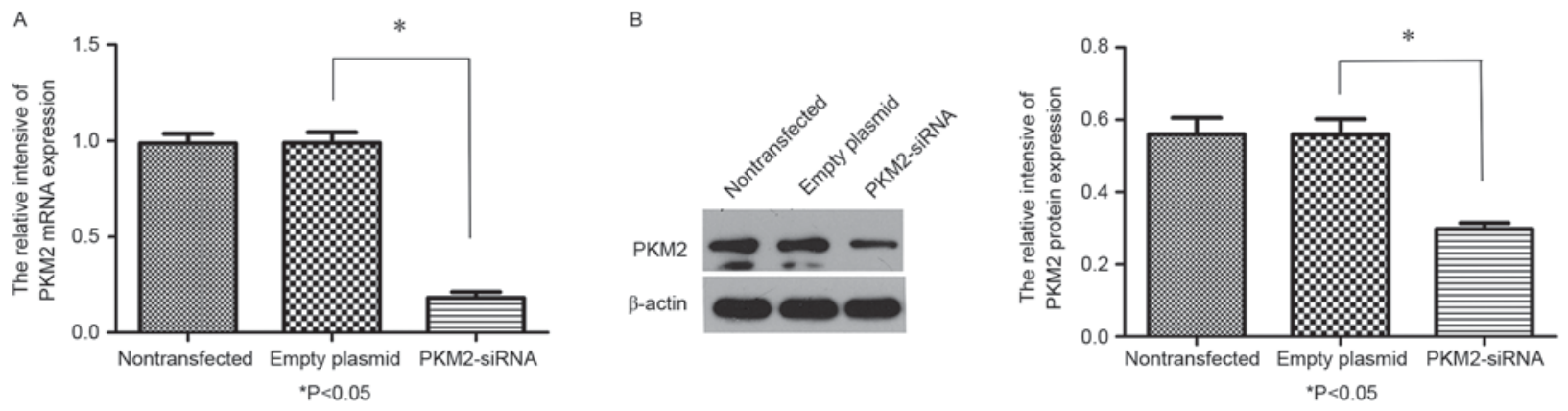

Figure 3. Knockdown of PKM2 in SGC-7901 cells transfected with siRNA. (A) Reverse transcription-quantitative polymerase chain reaction analysis indicated a significant decrease in PKM2 mRNA levels in SGC-7901 cells following transfection. (B) Western blot analysis validated a significant suppression of PKM2 expression following transfection. " $\mathrm{P}<0.05$ vs. empty plasmid. PKM2, pyruvate kinase M2; siRNA, small interfering RNA.
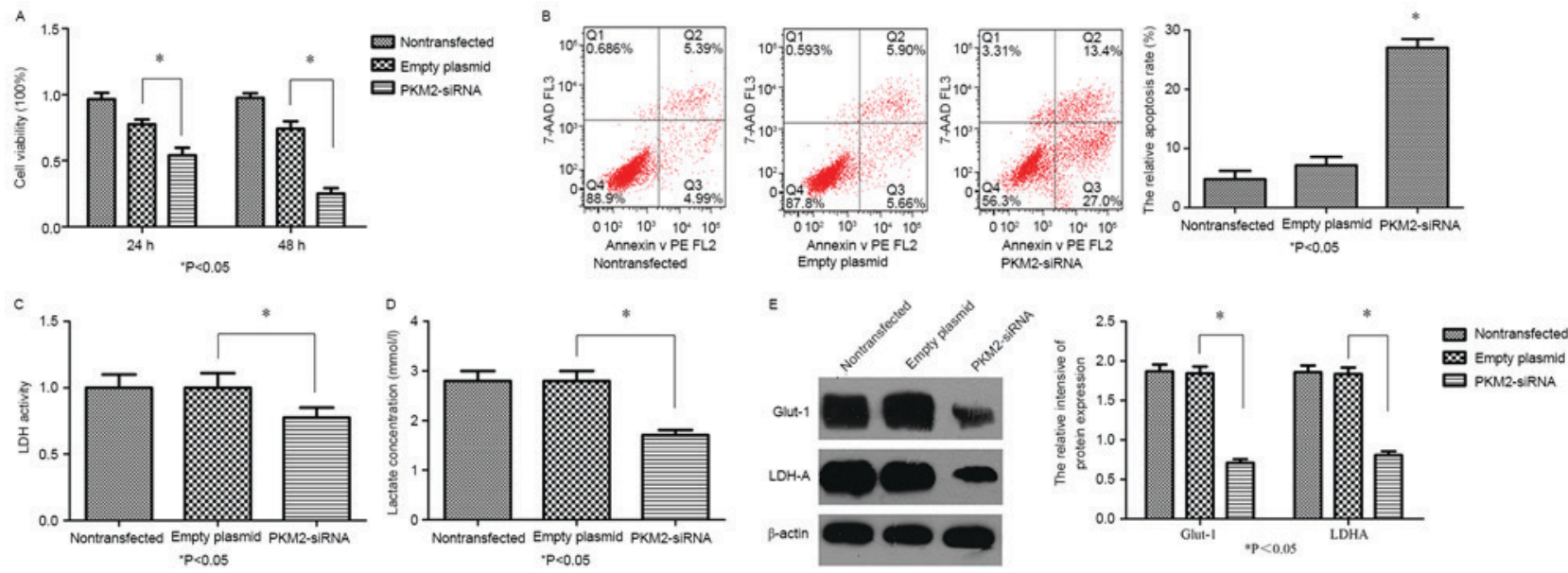

Figure 4. PKM2-knockdown inhibited cell proliferation, induced apoptosis and reversed the Warburg effect in SGC-7901 cells. (A) Cell Counting Kit-8 assay analysis of the effect of PKM2 on cell proliferation. (B) Flow cytometry analysis of the effect of PKM2 on the early apoptotic rate in SGC-7901/PKM2-siRNA-transfected cells, ${ }^{*} \mathrm{P}<0.05$ vs. control. (C) LDH activity in PKM2-siRNA-transfected cells was significantly decreased compared with in the control. (D) Lactate production of the PKM2-siRNA group was significantly decreased compared with in the control group. (E) Glut-1 and LDHA protein expression in SGC-7901 cells, as detected via western blotting, was significantly downregulated. P<0.05 vs. control. PKM2, pyruvate kinase M2; siRNA, small interfering RNA; LDH, lactate dehydrogenase; Glut-1, glucose transporter-1; LDHA, lactate dehydrogenase A.

including GC (32-38). Therefore, inhibition of this signaling pathway is widely considered as an attractive anticancer therapeutic strategy. In the present study, we demonstrated that a specific P13K inhibitor, LY294002, inhibited the proliferation, and increased the early apoptotic rate, of BGC-823 cells in vitro. Furthermore, it was observed that LDH activity and lactate production was inhibited by LY294002 in BGC-823 cells. Therefore, targeting the P13K/Akt/mTOR pathway may suppress cell proliferation and induce apoptosis, and thus reduce metastasis.

Targeting of the aerobic glycolysis (Warburg effect) pathway is considered to be a potential promising anticancer strategy (39). PKM2 is an essential glycolytic enzyme in this pathway, which alters the Warburg effect of tumor cells. PKM2 is overexpressed in diverse types of cancer cells (13-20). Accumulating data has demonstrated that increased PKM2 expression may contribute to the rapid growth of tumors, and induce apoptosis in multiple types of human cancer, including GC (36-45). PKM2 is a critical downstream target of P13K/Akt/mTOR signaling pathway $(46,47)$. In the present study, we observed significantly increased PKM2 expression in GC cell lines (SGC-7901, BGC-823), which is indicative of the importance of PKM2 to GC progression. The present study also revealed that LY294002 reduced p-Akt, p-mTOR and HIF- $1 \alpha$ protein expression in BGC-823 cells, and inhibited PKM2 protein expression, following high concentration (50 $\mu \mathrm{mol} / \mathrm{l}$ ) treatment. These data suggest that LY294002 may reduce tumor cell proliferation and aerobic glycolysis by inhibiting the P13K/Akt/mTOR/PKM2 signaling pathway.

To verify that PKM2 mediates the effects of LY294002 on GC cell proliferation, apoptosis and metastasis, we transfected a PKM2-knockdown plasmid into SGC-7901 cells. It was confirmed that cell proliferation was suppressed in the cells transfected with this siRNA-PKM2. We further demonstrated that PKM2-knockdown increased the early apoptosis rate of SGC-7901 cells. Furthermore, the results from the present study also demonstrated that downregulation of PKM2 significantly decreased LDH activity and lactate production; and that it reduced Glut-1 and LDHA protein expression levels. These data suggest that LY294002 was able to inhibit GC cell proliferation, induce apoptosis and reduce the Warburg effect, partly by inhibiting PKM2.

In conclusion, the present study demonstrated significantly increased PKM2 expression in GC cell lines, and revealed 
that LY294002 markedly inhibited the proliferation, induced the apoptosis and inhibited the Warburg effect of GC cells. Therefore, the anticancer activities of LY294002 may be partly linked to the downregulation of PKM2.

\section{Acknowledgements}

The present study was supported by the Outstanding Youth Project of Nanjing City (grant no. JQX14005) and the National Science Foundation (grant nos. 81272742, 81401974, 81400306 and 81401977).

\section{References}

1. Wadhwa R, Song S, Lee JS, Yao Y, Wei Q and Ajani JA: Gastric cancer-molecular and clinical dimensions. Nat Rev Clin Oncol 10: 643-655, 2013.

2. Torre LA, Bray F, Siegel RL, Ferlay J, Lortet-Tieulent J and Jemal A: Global cancer statistics, 2012. CA Cancer J Clin 65: 87-108, 2015.

3. Masoudi-Nejad A and Asgari Y: Metabolic cancer biology: Structural-based analysis of cancer as a metabolic disease, new sights and opportunities for disease treatment. Semin Cancer Biol 30: 21-29, 2015.

4. Pavlova NN and Thompson CB: The emerging hallmarks of cancer metabolism. Cell Metab 23: 27-47, 2016.

5. Shen CT, Wei WJ, Qiu ZL, Song HJ and Luo QY: Afamin promotes glucose metabolism in papillary thyroid carcinoma. Mol Cell Endocrinol 434: 108-115, 2016.

6. Jan CI, Tsai MH, Chiu CF, Huang YP, Liu CJ and Chang NW: Fenofibrate suppresses oral tumorigenesis via reprogramming metabolic processes: Potential drug repurposing for oral cancer. Int J Biol Sci 12: 786-798, 2016.

7. Navarro P, Bueno MJ, Zagorac I, Mondejar T, Sanchez J, Mourón S, Muñoz J, Gómez-López G, Jimenez-Renard V, Mulero F, et al: Targeting tumor mitochondrial metabolism overcomes resistance to antiangiogenics. Cell Rep 15: 2705-2718, 2016.

8. Li Z, Yang P and Li Z: The multifaceted regulation and functions of PKM2 in tumor progression. Biochim Biophys Acta 1846: 285-296, 2014.

9. Jurica MS, Mesecar A, Heath PJ, Shi W, Nowak T and Stoddard BL: The allosteric regulation of pyruvate kinase by fructose-1,6-bisphosphate. Structure 6: 195-210, 1998.

10. Tamada M, Suematsu M and Saya H: Pyruvate kinase M2: Multiple faces for conferring benefits on cancer cells. Clin Cancer Res 18: 5554-5561, 2012.

11. Christofk HR, Vander Heiden MG, Harris MH, Ramanathan A, Gerszten RE, Wei R, Fleming MD, Schreiber SL and Cantley LC: The M2 splice isoform of pyruvate kinase is important for cancer metabolism and tumour growth. Nature 452: 230-233, 2008.

12. Christofk HR, Vander Heiden MG, Wu N, Asara JM and Cantley LC: Pyruvate kinase M2 is a phosphotyrosine-binding protein. Nature 452: 181-186, 2008.

13. Liu WR, Tian MX, Yang LX, Lin YL, Jin L, Ding ZB, Shen YH, Peng YF, Gao DM, Zhou J, et al: PKM2 promotes metastasis by recruiting myeloid-derived suppressor cells and indicates poor prognosis for hepatocellular carcinoma. Oncotarget 6: 846-861, 2015.

14. Mukherjee J, Ohba S, See WL, Phillips JJ, Molinaro AM and Pieper RO: PKM2 uses control of HuR localization to regulate p27 and cell cycle progression in human glioblastoma cells. Int J Cancer 139: 99-111, 2016.

15. Wong N, Yan J, Ojo D, De Melo J, Cutz JC and Tang D: Changes in PKM2 associate with prostate cancer progression. Cancer Invest 32: 330-338, 2014

16. Shashni B, Sakharkar KR, Nagasaki Y and Sakharkar MK: Glycolytic enzymes PGK1 and PKM2 as novel transcriptional targets of PPAR $\gamma$ in breast cancer pathophysiology. J Drug Target 21: 161-174, 2013.

17. Yu G, Yu W, Jin G, Xu D, Chen Y, Xia T, Yu A, Fang W, Zhang X, Li Z and Xie K: PKM2 regulates neural invasion of and predicts poor prognosis for human hilar cholangiocarcinoma. Mol Cancer 14: 193, 2015.
18. Chen G, Feng W, Zhang S, Bian K, Yang Y, Fang C, Chen M, Yang J and Zou X: Metformin inhibits gastric cancer via the inhibition of HIF1 $\alpha /$ PKM2 signaling. Am J Cancer Res 5: 1423-1434, 2015.

19. Gao Y, Xu D, Yu G and Liang J: Overexpression of metabolic markers HK1 and PKM2 contributes to lymphatic metastasis and adverse prognosis in Chinese gastric cancer. Int J Clin Exp Pathol 8: 9264-9271, 2015.

20. Tang R, Yang $\mathrm{C}$, Ma X, Wang Y, Luo D, Huang C, Xu Z, Liu P and Yang L: MiR-let-7a inhibits cell proliferation, migration, and invasion by down-regulating PKM2 in gastric cancer. Oncotarget 7: 5972-5984, 2016.

21. Luo W and Semenza GL: Emerging roles of PKM2 in cell metabolism and cancer progression. Trends Endocrinol Metab 23: 560-566, 2012.

22. Panasyuk G, Espeillac C, Chauvin C, Pradelli LA, Horie Y, Suzuki A, Annicotte JS, Fajas L, Foretz M, Verdeguer F, et al: PPAR $\gamma$ contributes to PKM2 and HK2 expression in fatty liver. Nat Commun 3: 672, 2012.

23. Chen L, Shi Y, Liu S, Cao Y, Wang X and Tao Y: PKM2: The thread linking energy metabolism reprogramming with epigenetics in cancer. Int J Mol Sci 15: 11435-11445, 2014.

24. Shuch B, Linehan WM and Srinivasan R: Aerobic glycolysis: A novel target in kidney cancer. Expert Rev Anticancer Ther 13: 711-719, 2013.

25. Sun Q, Chen $X$, Ma J, Peng $H$, Wang F, Zha X, Wang $Y$, Jing Y, Yang H, Chen R, et al: Mammalian target of rapamycin up-regulation of pyruvate kinase isoenzyme type M2 is critical for aerobic glycolysis and tumor growth. Proc Natl Acad Sci USA 108: 4129-4134, 2011.

26. García-Carracedo D, Villaronga MÁ, Álvarez-Teijeiro S, Hermida-Prado F, Santamaría I, Allonca E, Suárez-Fernández L, Gonzalez MV, Balbín M, Astudillo A, et al: Impact of $\mathrm{PI} 3 \mathrm{~K} / \mathrm{AKT} / \mathrm{mTOR}$ pathway activation on the prognosis of patients with head and neck squamous cell carcinomas. Oncotarget 7: 29780-29793, 2016.

27. Chen S, Fisher RC, Signs S, Molina LA, Shenoy AK, Lopez MC, Baker HV, Koomen JM, Chen Y, Gittleman H, et al: Inhibition of PI3K/Akt/mTOR signaling in PI3KR2-overexpressing colon cancer stem cells reduces tumor growth due to apoptosis. Oncotarget 8: 50476-50488, 2016.

28. Petrov A, Beer M and Blome S: Development and validation of a harmonized TaqMan-based triplex real-time RT-PCR protocol for the quantitative detection of normalized gene expression profiles of seven porcine cytokines. PLoS One 9: e108910, 2014.

29. Livak KJ and Schmittgen TD: Analysis of relative gene expression data using real-time quantitative PCR and the 2(-Delta Delta C(T)) method. Methods 25: 402-408, 2001.

30. Bauer TM, Patel MR and Infante JR: Targeting P13Kinase in cancer. Pharmacol Ther 146: 53-60, 2015

31. Ying J, Xu Q, Liu B, Zhang G, Chen L and Pan H: The expression of the PI3K/AKT/mTOR pathway in gastric cancer and its role in gastric cancer prognosis. Onco Targets Ther 8: 2427-2433, 2015.

32. Zhu L, Derijard B, Chakrabandhu K, Wang BS, Chen HZ and Hueber AO: Synergism of PI3K/Akt inhibition and Fas activation on colon cancer cell death. Cancer Lett 354: 355-364, 2014.

33. Denoyelle C, Lambert B, Meryet-Figuière M, Vigneron N, Brotin E, Lecerf C, Abeilard E, Giffard F, Louis $\mathrm{MH}$ Gauduchon P, et al: miR-491-5p-induced apoptosis in ovarian carcinoma depends on the direct inhibition of both BCL-XL and EGFR leading to BIM activation. Cell Death Dis 5: e1445, 2014.

34. Houédé N and Pourquier P. Targeting the genetic alterations of the PI3K-AKT-mTOR pathway: Its potential use in the treatment of bladder cancers. Pharmacol Ther 145: 1-18, 2015.

35. Wang L, Wu J, Lu J, Ma R, Sun D and Tang J: Regulation of the cell cycle and PI3K/Akt/mTOR signaling pathway by tanshinone I in human breast cancer cell lines. Mol Med Rep 11: 931-939, 2015.

36. Li Y, Zhang Z, Zhang X, Lin Y, Luo T, Xiao Z and Zhou Q: A dual PI3K/AKT/mTOR signaling inhibitor miR-99a suppresses endometrial carcinoma. Am J Transl Res 8: 719-731, 2016.

37. Su CC and Chiu TL: Tanshinone IIA decreases the protein expression of EGFR and IGFR blocking the PI3K/Akt/mTOR pathway in gastric carcinoma AGS cells both in vitro and in vivo. Oncol Rep 36: 1173-1179, 2016.

38. Riquelme I, Tapia O, Espinoza JA, Leal P, Buchegger K, Sandoval A, Bizama C, Araya JC, Peek RM and Roa JC: The gene expression status of the PI3K/AKT/mTOR pathway in gastric cancer tissues and cell lines. Pathol Oncol Res 22: 797-805, 2016 
39. Yu L, Chen X, Wang L and Chen S: The sweet trap in tumors: Aerobic glycolysis and potential targets for therapy. Oncotarget 7: 38908-38926, 2016.

40. Chu B, Wang J, Wang Y and Yang G: Knockdown of PKM2 induces apoptosis and autophagy in human A549 alveolar adenocarcinoma cells. Mol Med Rep 12: 4358-4363, 2015.

41. Sun H, Zhu A, Zhang L, Zhang J, Zhong Z and Wang F: Knockdown of PKM2 suppresses tumor growth and invasion in lung adenocarcinoma. Int J Mol Sci 16: 24574-24587, 2015.

42. He Y, Wang Y, Liu H, Xu X, He S, Tang J, Huang Y, Miao X, Wu Y, Wang Q and Cheng C: Pyruvate kinase isoform M2 (PKM2). participates in multiple myeloma cell proliferation, adhesion and chemoresistance. Leuk Res 39: 1428-1436, 2015.

43. Liu Q, Liang M, Liu T, Vuitton L, Zheng S, Gao X, Lu M, Li X, Sheyhidin I and Lu X: M2 isoform of pyruvate kinase (PKM2) is upregulated in Kazakh's ESCC and promotes proliferation and migration of ESCC cells. Tumour Biol 37: 2665-2672, 2016.

44. Mohammad GH, Olde Damink SW, Malago M, Dhar DK and Pereira SP: Pyruvate kinase M2 and lactate dehydrogenase a are overexpressed in pancreatic cancer and correlate with poor outcome. PLoS One 11: e0151635, 2016.
45. Lu W, Cao Y, Zhang Y, Li S, Gao J, Wang XA, Mu J, Hu YP, Jiang L, Dong P, et al: Up-regulation of PKM2 promote malignancy and related to adverse prognostic risk factor in human gallbladder cancer. Sci Rep 6: 26351, 2016.

46. Nemazanyy I, Espeillac C, Pende M and Panasyuk G: Role of $\mathrm{PI} 3 \mathrm{~K}, \mathrm{mTOR}$ and Akt2 signalling in hepatic tumorigenesis via the control of PKM2 expression. Biochem Soc Trans 41: 917-922, 2013.

47. Yang L, Hou Y, Yuan J, Tang S, Zhang H, Zhu Q, Du YE, Zhou M, Wen S, Xu L, et al: Twist promotes reprogramming of glucose metabolism in breast cancer cells through PI3K/AKT and p53 signaling pathways. Oncotarget 6: 25755-25769, 2015.

(i) $(9)$ This work is licensed under a Creative Commons Attribution-NonCommercial-NoDerivatives 4.0 International (CC BY-NC-ND 4.0) License. 